\title{
Las ciudades Hispanas ante la Guerra Civil
}

\author{
Josefa Martínez Mera *
}

\begin{abstract}
RESUMEN ABSTRACT
El presente trabajo supone un intento de valorar la actividad militar de César en Hispania en relación con la actitud de las ciudades afectadas por el desarrollo del conflicto bélico, observando la reacción de estas frente a un conflicto que les es totalmente ajeno pero que puede repercutir y repercutirá de una forma muy directa en la vida de sus comunidades.

The present work means a purpose to judge the militar activity of Caesar in Hispania with regard to the attitude of the cities affected by the armed conflict advance, observing their reaction to a conflict which was nothing to do with them, but which can have repercussions and will have repercussions directly in their communities life.
\end{abstract}

El desarrollo de una parte de la guerra civil romana entre César y Pompeyo en territorio hispano siempre ha despertado un notable interés debido a que plantea una cuestión dé gran importancia: el papel que a mediados del siglo । a.C. jugaban las dos provincias hispanas dentro del conjunto del estado romano republicano. La concepción que bajo la República se tenía de las distintas provincias se basaba en el derecho de conquista por Roma de esos territorios que eran objetos de explotación en beneficio de Roma, fiscal y económicamente. Sin embargo, ya hacia finales de este período republicano, las provincias empiezan a reclamar cierto grado de protagonismo dentro del conjunto, debido, en gran medida, a la presencia

* Universidad de Santiago de Compostela. 
de ciudadanos romanos o itálicos en estas provincias (soldados licenciados asentados en esos territorios en los que anteriormente habían luchado, sus familias, comerciantes que controlan los principales núcleos comerciales dentro de la provincia y la exportación de su producción a Roma, personal administrativo, etc...) que desean asimilar en lo posible su modo de vida al de la propia Roma.

Siempre se ha dicho que César era plenamente consciente de la importancia que las provincias suponian para Roma y que su objetivo era conseguir la integración de estas en el estado romano concediéndoles igual importancia económica y política, rompiendo de este modo el modelo republicano de sometimiento a Roma, e introduciendo de este modo cambios políticos que facilitarían la instauración del Imperio.

Lejos de estas intenciones políticas preconcebidas, lo cierto es que las provincias romanas, y entre ellas Hispania, crecían en importancia y Roma tenía que recurrir a ellas económica y militarmente, pues de ellas procedían las materias primas y una parte del ejército romano, que además, estaba residiendo en ellas.

\section{LA IMPORTANCIA DE LA ACTUACIÓN MILITAR DE CÉSAR EN HISPANIA}

El simple hecho del desarrollo de parte de la guerra civil en territorio hispanc tiene de por sí una especial relevancia para los historiadores que tratan este tema, tanto debido a la importancia que supone que los asuntos internos romanos sobrepasen el marco estrictamente itálico, tomando una dimensión más amplia -las provincias-, como por el hecho de hacer de Hispania el primer escenario provincial de esta guerra.

La estancia militar de César en Hispania tiene lugar en dos momentos sucesivos: primeramente en el año 49 a.C., con el estallido de la guerra civil, cuando llega a la península para hacer frente a los legados de Pompeyo enviados por este nada más comenzar la guerra para organizar al ejército que tenía acantonado en este territorio, mientras él huía a las provincias orientales con similar objetivo y probablemente también para organizar una flota de ataque.

Se abren pues dos frentes diferentes a los que César debe atender para solucionar el conflicto. Es curioso que este gran estratega escogiese primeramente dirigirse al frente occidental, considerándolo como el más peligroso, puesto que los ejércitos organizados de los tres legados de Pompeyo (Afranio, Petreyo y Varrón) podrían lanzar un ataque a la Galia, provincia de César, y desde allí tomar Italia y Roma. También Pompeyo 
podría dirigir un ataque a la península itálica, pero era más peligroso el ataque de los legados, puesto que con la Galia en poder pompeyano, César no tendría ninguna posibilidad de continuar la guerra, ya que gran parte de su apoyo militar procedía de allí.

Dentro de Hispania, la historiografía siempre ha destacado como claves dos episodios militares: la batalla de llerda -referida en la propia obra de César (Bell. Civ. I, XXXIX-LXXXIV), que supone la derrota de las tropas de los legados de Pompeyo en la península al comienzo de la guerra civil (año 49 a.C.), y la batalla de Munda —relatada en el Bellum Hispaniense-, que supone la derrota de los hijos de Pompeyo que habían activado un foco de rebeldía en el sur de Hispania después de la victoria de llerda, en los años 46-45 a.C.

El tratamiento que la historiografía le ha concedido a estos dos episodios peninsulares es quizás mayor del que supuso en su momento para los propios romanos.

Nosotros intentamos valorar la importancia de esta acción de César en la península, puesto que, aunque suponen logros importantes dentro del contexto bélico para el control y dominio político de Roma, nos parece a un nivel más general, tomando como referencia todo el ámbito provincial romano que son episodios de importancia relativa frente a otros como la batalla de Dyrrachium (actual Durazzo) frente a las tropas del general Pompeyo, o incluso, la propia Farsalia, que pone punto final al conflicto.

Para aportar otro punto de vista sobre la relevancia de estos acontecimientos hispanos, proponemos analizarlos no en sí mismos como se viene haciendo tradicionalmente, es decir, valorándolos en su contexto hispano, si no que realizaremos un pequeño análisis comparativo de un episodio hispano con otro oriental, dos momentos distintos de esta guerra civil romana, para determinar la importancia de las contiendas sucedidas en suelo hispano frente a las otras provincias, en este caso las orientales, a donde huyó Pompeyo desde el puerto de Brindisi.

De entre todas las batallas susceptibles de analizar, tomaremos dos que aparecen relatadas en la guerra civil ( $D e$ Bello Ciuile) de Julio César, las batallas de Ilerda (Bell. Civ. I, LXXXIII) - actual Lérida- y de Dyrrachium (Bell. Civ.III, XLIV) --actual Durazzo, Albania-, frente a otras quizás más famosas o conocidas como Munda y Farsalia pero que cuyo relato no salió del propio stilus (equivalente de nuestra pluma) de César, sino que se deben a autores anónimos, posiblemente soldados de César: el Bellum Hispaniense, quizás de la autoría de un lugarteniente llamado Hircio, y el anónimo del Bellum Alexandrinum. Por otra parte, estas dos batallas también son significativas dentro de sus respectivos contextos 
particulares, ya que suponen un "punto de inflexión» en los acontecimientos, habiendo un antes y un después en términos militares.

En cambio, la obra de César es destacable por su rigor en la narración y descripción de cada uno de los episodios, por lo que se ha señalado que el texto podría proceder del propio diario de campaña del general, aunque, eso sí, debido al valor divulgativo y propagandístico de la obra (fue escrita para «informar» al pueblo romano de las virtudes de Julio César, salvador de Roma, frente a Pompeyo, enemigo de la patria) no es totalmente fiable, sobre todo en la relación de datos puntuales como el número de bajas en las filas de César o el de capturados o desertores de las filas enemigas.

\section{LA BATALLA HISPANA DE ILERDA Y LA DE DYRRACHIUM}

Para abordar nuestro análisis, primeramente prestaremos atención a los relatos propiamente de las batallas, especialmente en lo que se refiere a: las técnicas militares empleadas, los planes de ataque, los ánimos de los soldados... En el caso de la batalla de Ilerda, los hechos militares son tratados de una manera escueta y rápida, sin detenerse en cuestiones específicas de la preparación y desarrollo de la batalla, como sí sucede en el caso de la batalla de Dyrrachium o del asedio de Marsella. En Dyrrachium César nos cuenta cómo se colocaban las tropas (Bell. Civ. III, XLIV ; XLV), y cómo se les van dando las diferentes órdenes en el transcurso de la batalla; en el caso de llerda estas información militares son más bien de movimientos generales de todo el ejército, y la preocupación principal se centra en cuestiones de abastecimiento de trigo (I, XLVIII; LII) y de la construcción de puentes «estratégicos» militarmente sobre el río Segre (I, $\mathrm{XL}$ ) debido a que las malas condiciones climatológicas (riadas) provocaron la destrucción de los ya existentes.

Por otra parte, Dyrrachium se lleva a cabo un nuevo planteamiento bélico (Bell. Civ. III, XLVII, 1) consistente en la utilización de un gran número de fuertes y la forma de cercar un espacio especialmente grande. Además el episodio tenía su importancia debido a que las tropas que establecían el cerco eran mucho menores en volumen a las cercadas, y estas estaban bien provistas de abastecimientos, mientras que las de César padecian la escasez.

llerda es una batalla en la que se enfrentan sólo algunas de las tropas de César (puesto que parte de su ejército lleva a cabo el simultáneo asedio de Marsella) contra las tropas de los legados pompeyanos enviados a Hispania para proteger una provincia que le había sido asignada a Pompeyo. 
En cambio Dyrrachium supone un enfrentamiento de los ejércitos completos de César y Pompeyo, estando además este al frente de sus tropas propias tropas.

Por ello podemos decir que la batalla de llerda tiene una importancia o trascendencia militar menor debido a que la calidad de los ejércitos enfrentados es muy diferente a la de otras campañas: en llerda se enfrentan parte de las tropas de ambos ejércitos y las pompeyanas están bajo las órdenes de legados, en Dyrrachium, están presentes los ejércitos enteros con sus respectivos generales. Por esta razón, en llerda no se mencionan ni los estandartes con las águilas ni las enseñas de las legiones (insignibus imperatoriis), que sí aparecen en Dyrrachium (Bell. Civ. III, XCVI, 3) ${ }^{1}$, puesto que estos distintivos son propios de las legiones y del general, respectivamente; en Ilerda únicamente estarían sobre el campo las insignias de César, a las que no se hace referencia en el relato al no ser capturadas por los enemigos. Es importante señalar que en el ejército antiguo el valor de estos distintivos militares era enorme, ya que en la concepción de la guerra para los romanos la victoria se alcanza con la consecución de las insignias del ejército enemigo y se valora la magnitud del éxito de una batalla por el número de estandartes y águilas apresados ${ }^{2}$ (cf. Bell. Civ. III, $\mathrm{XCIX}, 3)$. Las insignias están presentes cuando el ejército es dirigido por su general. En este caso de llerda no está Pompeyo y por ello no hay ${ }^{3}$.

La importancia que la política y las relaciones de amistad o clientela tenían en el mundo romano son fundamentales en el caso de la batalla de Dyrrachium (Bell. Civ. III, LX,4 ; III, LXXVIII, 1), y, sin embargo, están casi literalmente ausentes en el caso de la batalla de llerda (tan sólo se hace una pequeña mención en Bell. Civ.l, XLVIII, 4). Lo mismo sucede si la comparamos con el episodio de Marsella, en el que es fundamental la participación de los ciudadanos de Marsella en el conflicto para su resolución. Además César tiene a sus aliados como bases de apoyo en puntos estratégicos fuera del territorio de la batalla, cubriendo así mayor parte del territorio (Bell. Civ.III, LXXVIIi,1) ; podríamos decir que en Oriente, César utiliza más — si comparamos con Hispania- el recurso a los alia-

\footnotetext{
La única referencia que se hace a ellas en Ilerda es a las insignias de César (I,XL,7 ; I,XLIil, 3 y 5$)$.

Las signa militaria (insignias militares) de los romanos eran el aquila (aguila), insignia de la legión, el signum (una punta de lanza con dos cintas pendientes decoradas en forma de hojas de hiedra), que pertenecía a las unidades inferiores, el manípulo y la cohorte, y las uexilla (estandartes con inscripciones), que identificaban a la caballería.

3 Para el caso de Hispania, aparece referida en el Bellum Hispaniense un momento en el que sí están presentes las insignias militares en el campo de batalla: en la batalla de Ategua, en la que César se enfrenta a Cneo Pompeyo, hijo del general (Bell.Hisp. VII, 4).
} 
dos, que tienen una participación más directa en el conflicto romano, con numerosas referencias a los aliados y su participación en las campañas (aportando soldados y avituallamiento para las tropas), que en el caso hispano, donde, en el ejemplo de la analizada batalla de llerda, la ciudad parece quedarse al margen de toda acción, en la que los verdaderos protagonistas son los soldados, y las referencias que se hacen en este pasaje son más bien de carácter militar movimientos de tropas de las cercanías de llerda a Otobesa y otra vez a llerda (Bell. Civ. I,LXI, 5 ; I, LXXVIII).

Ilerda carece de esta presencia de civiles en el relato bélico, y por tanto se queda en sólo un mero enfrentamiento militar entre tropas, sin mayor aliciente que el puramente militar.

El propio César en su obra nos hace una valoración más bien negativa de aspectos militares concretos de este episodio. Así, en De Bello Ciuile nos dice: "el modo de combatir de aquellas tropas era salir corriendo al principio con gran impetu, apoderarse audazmente de un lugar, no conservar su formación cuidadosamente y luchar aislados y dispersos ; (...) no consideraban vergonzoso retroceder $y$ abandonar el lugar $(. .)^{4}$ ", haciendo referencia a la forma de luchar que tenían las tropas de Afranio y Petreyo, compuestas por ciudadanos romanos que llevaban mucho tiempo viviendo en suelo peninsular ${ }^{5}$ y por tropas auxiliares hispanas. Supone esta una forma no sólo de luchar, sino de entender el concepto de guerra que era extraño para los romanos, enfrentado a unas tropas cuyos métodos bélicos eran diferentes.

Quizá con todo esto estamos poniendo de relieve la «excesiva» importancia que se le ha dado a la campaña de Hispania, tal vez por ser la primera tratada en el corpus caesariano, ya que es el primer objetivo de César después de hacerse con el control militar de Italia. Pero, sin quitarle su importancia, que la tiene por ser el inicio de la guerra civil proyectada a las provincias, hay que analizar con justicia su relevancia dentro del conjunto del conflicto, sabiendo reconocer su relativo carácter secundario frente a otros episodios de la guerra. No por ser el «primer escenario provincial» hay que magnificar su interés e importancia.

Vista así, llerda sería una batalla de importancia relativa dentro de todo el contexto militar romano, puesto que se luchó contra un grupo de tropas bárbaras o «barbarizadas», que no compartían el ars belli romano.

4 Bell.Civ. 1, XLIV,1: «Genus erat pugnae militum illorum, ut magno impetu primo procurrerent, audacer locum caperent, ordines suos non magnopere seruarent, rari dispersique pugnarent; si premerentur, pedem referre et loco non turpe existimarent...".

5 En Hispania había cohortes de ciudadanos romanos. Cf. Bell. Civ. III, X, 5. 
Pero también tenemos que ver cuál es la valoración del propio César: mientras relata el episodio de Dyrrachium hace una referencia general a la conquista de Hispania: "...los soldados aguantaban estas dificultades con singular paciencia. Pues recordaban que el año anterior había sufrido en España la misma escasez, y sin embargo, por su trabajo y paciencia, habian ganado una guerra importante" ${ }^{6}$. De esta mención se deduce que César analiza conjuntamente los enfrentamientos que tuvieron lugar en la península, ya que en todas las batallas libradas en Hispania se encontró siempre con unas características similares, tanto de paisaje como de tropas oponentes. No destaca en especial ningún episodio concreto, aunque sin duda la acción militar de mayor envergadura fue la que se llevó a cabo en Lérida y sus alrededores.

César se vanagloria de haber conseguido esta victoria, pero ¿por qué lo hace?; debemos atender a un dato: César no dice que esta victoria la ha ganado él (como hace en episodios dignos de resaltar su fama, en los que atribuye el éxito de la contienda sólo a su genio ${ }^{7}$, sino que dice que la han ganado sus soldados. Se trata de un recurso literario para atraerse a la opinión pública del momento y ganarse más adhesiones entre sus seguidores, pero este artificio tan sólo lo usa en batallas que no son significativas; si la batalla fuese realmente importante para el devenir histórico de la guerra, se hubiera atribuido a su propio genio militar la victoria, como v.gr. Bellum Ciuile (también referido a Hispania): «...porque habia ganado las dos Hispanias habitadas por hombres aguerridos que además estaban mandados por jefes muy capacitados y experimentados, porque habian puesto bajo su dominio las provincias cercanas muy ricas en trigo ${ }^{8}$.

El profesor Roldán Hervás, gran especialista en temas del ejército romano, sobre todo dentro del período republicano, defiende la singularidad e importancia de la península ibérica como factor fundamental en el desarrollo de los acontecimientos militares (e incluso políticos) de la guerra civil. Él nos señala que: "Entre llerda y Munda... se desarrolla una lucha por el primer puesto en este imperio, que cambiaría incluso las bases estructurales políticas. Y ambos hitos pertenecen a la geografía política hispana. No es mero azar el que la primera y última prueba de

\footnotetext{
6 Bell.Civ. III, XLVII, 5: "Sed tamen haec singulari patientia milites ferebant. Recordabatur enim eadem se superiore anno in Hispania perpessos labore et patientia maximun bellum confecisse".

Cf. La obra de Rambaud, L'art de la déformation historique chez César, París, 1966.

\& Bell.Civ. III, LXXIII,3: "...quod duas Hispanias bellicosissimorum hominum peritissimis atque exercitatissimis ducibus pacauissent, quod finitimas frumentariasque prouincias in potestatem redegissent».
} 
fuerza entre César y el partido pompeyano tuvieran por escenario la $\mathrm{Pe}$ nínsula lbérica(...)»? .

Para el profesor Roldán estas dos batallas son decisivas en el transcurso de la guerra civil entre César y Pompeyo; sin embargo, nosotros pensamos que la importancia de estas dos batallas debe ser atenuada, puesto que, si bien no hay que negarle un gran significado dentro de los acontecimientos peninsulares, dentro del contexto general romano, tanto político como militar, no poseen la importancia o valor de "hitos claves", sino que suponen una serie de etapas para la consecución de un elemento de importancia en la guerra, el control de las provincias hispanas. Además tenemos dentro del contexto bélico peninsular otras batallas de un valor militar semejante; así en el Bellum Hispaniense se nos hace referencia a una batalla, la de Ategua (19 de febrero del 45 a.C.), que también revela una gran importancia desde el punto de vista militar, debido a que el enclave era e punto más fuerte de los pompeyanos en el sur peninsular que también revela gran importancia desde el punto de vista militar, o bien el episodio del asesinato de unos legados romanos capturados en Ategua por los ursaonenses (Bell. Hisp., I, 22). También fuera de la península hay episodios muy relevantes de importancia igual o superior a estas dos batallas peninsulares «magnificadas» — llerda y Munda-; hablamos de la batalla de Dyrrachium (Durazzo) o incluso de la propia Farsalia.

Pensamos que la visión de Roldán, como la de la mayoría de los historiadores peninsulares, tiende a acentuar el papel de Hispania dentro del conjunto del Imperio, así como su singularidad e importancia dentro de la política romana, pero un análisis de conjunto de los hechos nos induce a pensar que, si bien no se puede negar la importancia de estos acontecimientos que tienen lugar en Hispania, deben valorarse sin perder de vista que forman parte de un teatro de operaciones mediterráneo donde hay multiplicidad de escenarios y situaciones.

¿Por qué no nos hemos parado a pensar en la posibilidad de la casualidad para ciertos hechos militares acaecidos dentro de la península ibérica, y también -y por extensión-para la elección de la península ibérica como escenario de las operaciones militares?

Que la península ibérica haya sido el objetivo primero que aparece reflejado como escenario de la guerra civil en el relato cesariano tras salir de la península itálica, no nos debe llevar a equivocaciones a la hora de valorar la importancia de este en el contexto general, ya que, aunque la obra de

9 Roldan Hervas, J.M.: Ejército y sociedad en la España romana, Granada, 1989, pág. 150. 
César empieza prácticamente su relato bélico en Hispania, la guerra civil había comenzado antes, con la toma de Italia, y hay que tener también en cuenta que los preparativos de esta guerra se llevaron a cabo en la Galia.

Además, no sería lógico "engrandecer" demasiado la importancia de las provincias, o en este caso de una provincia, en este conflicto, ya que, si bien es una de las primeras veces (antes con las guerras sertorianas) que estas entran de una forma clara en el juego de los intereses políticos romanos (debido a la importancia, riqueza e influencia que iban adquiriendo algunos provinciales), no hay que olvidar que este conflicto con escenario provincial surgió para hacerse con el control de la propia Roma.

Al hablar de "elección» de la península como escenario de la guerra civil estamos haciendo referencia indirectamente a la existencia de una especie de «plan preconcebido de ataque» al menos por parte de una de las dos facciones. Bien es cierto que la llegada de los pompeyanos a Hispania tenía una serie de elementos a favor que pudieron "conducir» el devenir histórico; y es que no debemos olvidar que hay cierta intencionalidad de Pompeyo por enviar a sus legados a Hispania para hacerse cargo de las tropas que tenía alli "acantonadas", unas tropas que fue formando gracias a su relación con la penínsulas desde el año 54 a.C. en el que fue nombrado gobernador. Sin embargo, el hecho de que fuera la península ibérica y no otra provincia del naciente imperio no responde a ningún «plan»; hubiera sucedido lo mismo, pero con otro destino geográfico, si Pompeyo fuera gobernador, por ejemplo, de Siria.

Además en la península Pompeyo tenía formada una red, que se supone bastante extensa, de lazos clientelares fraguados con motivo de su estancia en la misma durante las guerras sertorianas, que fueron incrementadas por él desde el año 54 a.C. Y por otra parte, Hispania contaba con ciudades aliadas romanizadas, en las que habia un importante elemento pro-senatorial.

A este respecto, el Bell.Civ. nos da algunas razones de esta «elección»: las fuerzas más importantes de Pompeyo estaban situadas en la península (Bell.Civ. I, XXXVIII, XXXIX), siendo mucho menores las tropas que habian abandonado Italia siguiendo a su general y que pasan con él a oriente. Además, corrían rumores de que Pompeyo intentaba entrar en Hispania a través de Mauritania (Bell.Civ. I , XXXIX,3).

Pero Pompeyo se marcha a Oriente nada más comenzar el conflicto y huye de Italia, y los enfrentamientos que se producen entre él y César tienen también lugar en las provincias orientales puesto que es César el que tiene que ir a él en busca del enfrentamiento bilateral. Asimismo su huída de César transcurre también dentro del ámbito geográfico oriental, desde 
el Ilirico hasta Egipto. Las provincias occidentales, reducidas a las dos Hispaniae ya que la Gallia era dominio de César, quedan en manos de legados suyos.

Se puede ver en este reparto de provincias entre él y sus generales una clara preferencia de Pompeyo por Oriente, explicable a través de una carta de Cicerón en la que se menciona la razón de su importancia : la flota. Pompeyo basaba su poder militar en las fuerzas navales y pretendía llevar el campo de batalla a las aguas donde tenía mayor ventaja ya que César prácticamente carecía de barcos, quien hay que recordar que hasta que vence a los legados de Pompeyo en Hispania no se hace con recursos navales (cuando vence a Varrón, se apodera de los trece barcos que este había mandado construir en Gades, Bell. Civ. II, 4).

La carta en cuestión dice así: "...Toda esta flota procedente de Alejandría, Cólquide, Tiro, Sidón, Arado, Chipre, Panfilia, Licia, Rodas, Quíos, Bizancio, Lesbos, Esmirna, Mileto, Cos, está destinada a interceptar los aprovisionamientos de Italia y a ocupar las provincias productoras de trigo" ${ }^{10}$.

Y parece que en este momento, en la valoración de los grupos superiores romanos, prima este factor, ya que se consideraba que el que tuviera el control del mar dominaría la situación bélica ${ }^{11}$. En este contexto hay entender la orden de Varrón a los gaditanos para la construcción de diez naves en su puerto (Bell.Civ. XVIII, 1).

De estas líneas se podría deducir que la intención de Pompeyo era controlar el abastecimiento de trigo, que llegaba a Roma por vía marítima, para obligar a César - quien ya era dueño de la ciudad - a rendirse o a pactar con él. A su vez también intentaría incrementar sus fuerzas y apoyos militares en esa región para hacerle frente a César, y, en este sentido, Cicerón se hace eco de la creencia, extendida entre los romanos, de que Pompeyo desde el llírico marcharía sobre la Gallia de César con sus tropas ${ }^{12}$.

10 Cicerón, C.T.: Cartas a Ático, 176 (IX, 9), 2, del 17 de marzo del 49 a.C.

¿1 El control marítimo se hace imprescindible después de la pérdida de las provincias hispanas por parte de Pompeyo. Ya hemos visto cómo ese control se lo facilita la posesión de las provincias orientales, mejor equipadas en recursos navales. Cicerón en su carta 199 (X, 8 ) 4 nos dice : "Deinde hoc uide, non esse iudicium de tota contentione in Hispaniis, nisi forte iis amissis arma Pompeium abiecturum putas, cuius omne consilium Themistocieum est. Existimat enim, qui mare teneat, eum necesse esse rerum potiri. Itaque numquam id egit, ut Hispaniae per se tenerentur, naualis apparatus ei semper antiquissima cura fuit." ("...ten en cuenta que la decisión de todo el conflicto no está en las provincias hispanas... quien tenga el mar dominará la situación. Esa es la razón de que nunca procurara tener las provincias hispanas por si mismas ; su primer cuidado fue siempre el aparato naval").

12 Cf. Cartas a Ático 197 (X, 6), 3 y 200 (X, 9), 1 
A pesar de esta preferencia oriental, sabemos que las provincias hispanas, dentro del contexto general de la guerra, eran importantes, ya que pasando a manos de César le proporcionaban el control de todo el occidente romano; por ello su pérdida por parte de los pompeyanos pone a estos en una situación dificil ${ }^{13}$.

César prácticamente no tenía ningún «punto de apoyo» en la península; se podría decir que llega aquí «forzado por las circunstancias». En la Guerra Civil se da a entender que César carecía de clientelas en Hispania, ya que en ningún momento se hace referencia a esta posibilidad, y la primera vez que se habla del tema se nos dice que tales relaciones surgieron como fruto de la estancia de Julio César en el territorio de llerda, ganándose el favor de las ciudades vecinas con su actuación (I, XLVIII,4). Sin embargo sabemos que esto no es así ya que César, antes de la guerra civil ya había tomado contacto con la península ibérica en calidad de cuestor y después como propretor, y, como nos relata Suetonio, practicó una política favorable con determinadas ciudades como fue el caso de Gades (Suet., XII, 2,4). Además en la provincia Ulterior se había creado una clientela militar y civil, a la cual se dirigió en su conocido discurso en Hispalis (Bell.Hisp. 42) y entre los que reclutó sus tropas auxiliares (Plutarco, Caes. 12).

Cortijo Cerezo ${ }^{14}$ nos señala que César contó con partidarios en las principales ciudades durante las guerras civiles a pesar de que las provincias permanecieron durante mucho tiempo bajo la órbita de poder de Pompeyo, indudablemente se trataba de ciudades del norte del Ebro que, como Osca, se pasaron al bando cesariano.

Siguiendo la opinión del profesor Roldán Hervás, la posesión de estas clientelas son un elemento fundamental y probablemente decisivo para la victoria de uno $u$ otro bando.

\section{LA ACTITUD DE LAS COMUNIDADES HISPANAS}

En las siguientes páginas intentaremos aproximarnos a la realidad vivida por las ciudades hispanas en el momento en el que tiene lugar el contacto con el conflicto civil romano para valorar el grado de participación

13 Id. $200 \mathrm{~A}(\mathrm{X}, 9 \mathrm{~A}), 3$ : "Quod si totum tibi persuadere non possum, saltem, dum, quid de Hispaniis agamus, scitur, expecta; quas tibi nuntio aduentu Caesaris fore nostras. Quam isti spem habeant amissis Hispaniis, nescio". ("...hasta que se sepa cómo nos van las cosas en relación con las provincias hispanas; las cuales te anuncio que con la llegada de César serán nuestras. Y no sé qué esperanza tienen éstos una vez perdidas las provincias hispanas...").

14 Cortiuo Cerezo: "El municipio de Ulia», Hispania Antiqua XIII, pág. 39. 
en el conflicto a favor de una o de otra facción político-militar romana, sus relaciones de clientela -escasamente referidas en el caso hispano-, y su actitud frente a los acontecimientos.

Para ello nos basaremos en las dos obras que relatan la guerra romana en suelo hispano: De Bello Ciuile de Julio César y Bellum Hispaniense anónimo, probablemente de Hircio, lugarteniente de César. Con estas dos obras se cubre todo el período bélico en Hispania. La obra de César, que sigue una descripción rigurosa de los hechos, relata el encuentro con los legados de Pompeyo en la ciudad de Lérida y la situación militar el sector nororiental de la península en conexión con el sureste de la provincia de la Galia, y extiende su escenario bélico a practicamente toda la provincia hispana Citerior, llegando desde Ilerda hasta Gades. El relato del lugarteniente nos narra episodios no abordados por César en su obra que se refieren a la lucha que continuó a la derrota de los legados de Pompeyo y que estuvo dirigida por los hijos del general, Cneo y Cayo, Ilegados a la Hispania. Estos enfrentamientos se desarrollan en un escenario íntegramente meridional, moviéndose siempre por diferentes ciudades del sur de la provincia Citerior, la futura Baetica de Augusto.

\section{De Bello Ciuile}

En esta obra de César en la que se nos relata la guerra civil en Hispania durante los años 49-48 a.C. aparecen mencionadas diferentes ciudades siguiendo el orden de desarrollo de la guerra. Hay que señalar que de la lectura de la obra de César se deduce que el itinerario que sigue la guerra, es decir, los lugares o ciudades afectados por el movimiento de tropas, está marcado por la elección de escenarios del bando pompeyano; César aparece como un elemento pasivo en este movimiento por la península, limitándose a seguir a sus enemigos. Esta visión particular de los acontecimientos le proporciona dos cosas: por un lado se nos muestra como un personaje sometido a las circunstancias de la guerra impuesta por sus enemigos (es como si el no tuviese ganas de luchar y de decidir la guerra), y por otro, deja al bando enemigo la impopular tarea de la elección de los lugares de lucha, siendo impopular desde el punto de vista que tendrían las poblaciones afectadas.

Cuando César se plantea venir con sus tropas a la península para hacerle frente a los legados de Pompeyo se dirige directamente hacia llerda pues este fue, como él mismo dice, el escenario escogido por Afranio y Petreyo ${ }^{15}, y$,

\footnotetext{
15 Bell. Civ. I, XXXVIII, 3 : Constituunt communi consilio bellum ad llerdam propter ipsius loci opportunitatem gerere (Deciden de común acuerdo hacer la guerra en las proximidades de Lérida por las ventajas de este lugar).
} 
de un modo similar discurre después su deambular por las siguientes ciudades, como se nos muestra a través de los textos literarios, tanto en el Bell. Civ. como en el Bell. Hisp.

Por ello, creemos interesante mostrar una relación de itinerarios propuestos en cada una de las obras (ya que responden a momentos sucesivos en el tiempo) para así conocer los lugares que tuvieron como escenario la contienda entre César y los pompeyanos. Pretendíamos comprobar con ello si existía algún tipo de motivación ajena a la puramente bélica en la elección de estas ciudades, pero del análisis de las fuentes parece deducirse que más bien fue la propia guerra la que fue marcando el cambio de escenario dentro de la península:

llerda (Lérida) (Bell. Civ., XXXVIII, 4): la razón de tal elección que da el propio autor es que ese fue el lugar escogido por los pompeyanos para entablar batalla. Alí César recibe a unos 6.000 hombres que llegaban a la península (I, LI, 2), que en opinión de García y Bellido eran civiles ${ }^{16}$, aunque no pensamos que sea muy lógica una posible llegada de población civil a un campo de batalla en el que se lucha contra un grupo de «bárbaros» y en una época de frío y abundantes lluvias.

En esta ciudad César consigue la alianza de oscenses $-y$ también de sus tributarios, los calagurritanos-, tarraconenses, iacetanos, ausetanos e ilurgavonenses (pueblos a los que considera como «ciudades grandes»), que en virtud del pacto realizado le proporcionan trigo, bestias de carga y una cohorte de ilurgavonenses (I, LX).

Un hecho curioso que se menciona en esta parte del relato es la existencia de pactos de alianza por parte de Pompeyo, realizados en los años anteriores en los que la provincia le fue designada. César lo menciona para hacer referencia a su situación inferior con respecto a su adversario en el terreno de las alianzas ${ }^{17}$.

En el medio de la descripción de la batalla de llerda el autor interrumpe la narración e intercala el relato del asedio de Marsella (I, LVI-I, LIX); esto se ha señalado como un recurso para hacer ver al lector la simultaneidad de los dos acontecimientos bélicos.

\footnotetext{
16 Garcia Belioido, A. : Art.Cit, AHDE, 1959, pág. 473.

17 Caesar: Bell.Civ. I, LXI, 3: “... ex duobus contrariis generibus quae superiore bello cum Q.Sertorio steterant ciuitates uictae nomen atque imperium absentis timebant, quae in amicitia manserat, Pompeii magnis affectae beneficils eum diligebant, Caesaris autem erat in barbaris nomen obscurius» («...de los dos bandos contrarios en la anterior guerra contra $Q$. Sertorio, las ciudades vencidas temían el nombre y el poder de Pompeyo aún en su ausencia, y las que habían estado en su alianza le eran muy adictas por haber recibido grandes beneficios, sin embargo el nombre de César era menos conocido entre los bárbaros").
} 
Otobesa: situada junto al río Ebro. Distante 20.000 pasos del campamento de los pompeyanos en Lérida. Estos querían trasladar la guerra de Lérida a Otobesa para así conseguir llevarla a territorio de la Celtiberia, porque allí el nombre de Pompeyo aglutinaba más apoyos (I, LXI, 5), pero el plan no dió resultado por el hostigamiento de las tropas de César.

Corduba: César, por medio de un edicto, fija en esta ciudad una asamblea a la que deberán acudir magistrados y jefes de todas las ciudades (magistratus principesque omnium ciuitatum) de la Hispania Citerior (II, $X I X, 1)$. Con esto trata de asegurarse apoyos para hacer frente a los que ya tiene el bando contrario en la misma provincia (II, XVIII, 7). En esa asamblea, que duró dos días, da las gracias por los apoyos recibidos, perdonó las cantidades de dinero que los ciudadanos romanos habían prometido a Varrón para el erario, y restituyó los bienes confiscados. también concedió premios a algunas ciudades y a particulares que le apoyaron (II, XXI).

Alli Varrón capitula ante César; le entrega las cuentas públicas y el dinero (publicae rationes y pecunia) (II, XX, 8).

Carmo: Considerada por César como la ciudad más fuerte de toda la provincia (II, XIX,4). Cerró las puertas a Varrón y se pasó a César.

Gades: Ciudad famosa por su adhesión a César. Después de la victoria de César en llerda la ciudad estaba tomada por el pompeyano Galonio. Los jefes de la ciudad (Gaditanos principes) expulsan a Galonio de la ciudad y se la reservan para César (II, XX, 2-3). César restituye las riquezas del templo de Hércules, guardadas por causa de la guerra (II, XXI, 3). La ciudad recibió de César el estatus de municipio en el 49 a.C. (era procesariana ${ }^{18}$ ). Desde alli César partió hacia Tarraco.

Hispalis: Ciudad también cesariana adonde se retira la legio Vernacula tras abandonar a Varrón (II, XX, 4) y pasarse a César.

Italica: También apoyaba a César. Cerró sus puertas al ejército de Varrón (II, XX, 6).

Tarraco: Última escala de César en la península antes de abandonar la península, después de pacificar la provincia. se reunió con embajadas de toda la Citerior, como había hecho en Corduba, concediendo honores a ciudades y a particulares (II, XXI, 4-5). Probablemente celebra dos reuniones en la Citerior ante la imposibilidad de movilizar a toda la provincia en un sólo punto geográfico en el sur.

18 Cf. Brunt, P.A.: Italian Manpower 225BC- 14AD, Oxford 1971, pág. 602. 


\section{Bellum Hispaniense}

Utilizaremos esta obra para delimitar geográficamente la acción militar de los romanos en el sur peninsular, atendiendo especialmente a las ciudades que se vieron envueltas en el conflicto o que participaron activamente en él a favor de uno u otro bando. Hay que tener en cuenta que la obra no es el reflejo fiel de la situación urbana de la provincia, ya que hay muchas ciudades que ni siquiera se mencionan, pero nos sirve para intentar determinar las relaciones políticas y militares llevadas a cabo en relación a la guerra civil ${ }^{19}$.

Los acontecimientos que se nos relatan en esta obra se sitúan temporalmente unos años después de lo relatado en el Bellum Ciuile, en torno a los años 47-45 a.C. El rebrote de la guerra en Hispania se produce por la mala gestión de Q. Casio Longino, legado que deja César en la Citerior con cuatro legiones para controlar la provincia (Bell. Civ. I, XXI, 4). Los hijos de Pompeyo aprovechan ese malestar entre los provinciales para retomar la oposición militar a César. Haremos también una relación de los escenarios mencionados, como en el caso anterior con el Bell. Civ.:

Ulia: Ciudad cesariana citada en el capítulo III del Bell. Hisp. Su situación topográfica según el Bellum Hispaniense es «in edito monte», que se identifica generalmente con la actual Montemayor ${ }^{20}$, donde se han encontrado restos arqueológicos, epigráficos y numismáticos. En el Bell. Hisp. se cita a propósito de la resistencia que ofrece la ciudad a Cn. Pompeyo (III, 3), que tuvo que detenerse durante varios meses delante de sus murallas antes de la llegada de César, y esta fuerte resistencia es fruto de la actitud filocesariana de sus habitantes ("Caesar eam ciuitatem omni tempore optimae de populo romano memoria cum temeret»). Vlia ${ }^{21}$ fue la única ciudad que no optó por la facción pompeyana ${ }^{22}$.

César se entrevista con los de la ciudad (III, 3) y les envía como apoyo seis cohortes de infantería y caballería bajo las órdenes de Lucio Vibio Pacieco (III, 4).

19 Opinión que compartimos con los profesores González Román y Marín Díaz, quienes señalan que et Bellum Hispaniense «no constituye un documento de carácter geográfico, sino que la información que nos ofrece es básicamente de carácter politico-militar(...) el Bellum Hispaniense nos ilustra sobre el grado de desarrollo e implantación que el proceso de romanización-urbanización tiene en el sur de la península". Gonzalez Román, G., Marín Diaz, M.A.: Op.Cit, pág. 26.

20 Según González Roman, G. y Marin Díaz, Ma .A.: «El Bellum Hispaniense y la romanización del sur de la península". Hispania Antigua. XI-XII (1981-85). Universidad de Valladolid.

21 El parecido entre el nombre de la ciudad, Vlia, y el epíteto cesariano «Iulia» ya fue puesto de manifiesto en el siglo pasado por Hubner, en CIL II, Suppl. Pág. 870.

22 Según Dion Cassio, XLIII, 31, 4. 
Cneo Pompeyo desiste del asedio de la ciudad para ir en ayuda de su hermano Sexto en Corduba (IV,4).

Con posterioridad Plinio la nombra como «Fidentia», lo cual ha hecho suponer de que tendría el estatus de colonia o de municipio romano antes de Augusto (es decir, o bien en época de César o en los años siguientes, con Octavio), haciendo alusión con este epíteto a su fidelidad a César durante el período de la guerra en Hispania.

Corduba: Capítulo III del Bell. Hisp. donde se cita como capital de la provincia ("quod eius prouinciae caput esse existimatur»). Era uno de los baluartes fundamentales de los pompeyanos -allí Sexto tenía una guarnición. (III,1)-; César sólo logró hacerse con ella tras la batalla de Munda y después del aniquilamiento de 22.000 personas según el texto (cifra exagerada, pero que pone de relieve la importancia del hecho).

En el Bell.Civ. se alude a que en el año 49 a.C. existía en ella un "Conuentus Ciuium Romanorum» 23. Del análisis de estos datos la historiografía ${ }^{24}$ concluye que esta ciudad constituía en un principio un «conciliabulum ciuium romanorum» que con posterioridad obtendría el estatus de colonia bajo $\mathrm{Cn}$. Pompeyo, probablemente en los años 46-45 a.C., lo cual vendría a explicar la fuerte filiación o "devoción» a la figura de Pompeyo, lo cual les llevó a ofrecer una dura resistencia a César.

En época de Augusto se convierte en una colonia (Colonia Patricia Cordubà).

Ategua: Se dice de ella en el Bell. Hisp. VI,1 que es: "la fortaleza más fuerte del enemigo" ( «firmissimum eius praesidium»). Escenario de una importante batalla de César contra Cn. Pompeyo ; en ella también se pone en práctica la táctica de Pompeyo de huir dejando en llamas uno de sus campamentos, situado en los alrededores de la ciudad (VII, 1). César se apodera de la plaza fuerte de Ategua el 19 de febrero del 45 a.C., y, unos días después de este hecho, es proclamado imperator por sus tropas (cap. XIX).

El Bell. Hisp. registra la presencia de torres y fortificaciones cubiertas con grava (al modo de las de África, según se anota en la obra) así como de atalayas que se elevan sobre el paisaje controlando todas las direcciones (VIII, 3).

23 Caes. Bell. Civ. 1119,3

24 Sobre los diferentes aspectos del conuentus ciuium romanorum consultar las obras de Dopico Cainzos, Ma.D.: La Tabula Lougeiorum. Estudios sobre la implantación romana en Hispania, Vitoria-Gasteiz, 1988. Id.: "Los conuentus iuridici. Origen, cronologia y naturaleza histórica», Gerión 4, Madrid, 1986. 
También se hace referencia a la existencia de un primer muro de la ciudad ${ }^{25}$, lo que nos hace pensar en la posibilidad de que la ciudad de Ategua estuviera defendida por una doble muralla.

No hay ningún testimonio que haga referencia a su estatus jurídico.

Ucubis: (actual Espejo, a $35 \mathrm{Km}$. de Córdoba) Plaza de Pompeyo. Tras la rendición de Ategua, $C n$. Pompeyo traslada aquí su campamento $(X X, 1)$ y también se hace menciona en la obra la división que existía en la ciudad entre los bandos de pompeyanos y cesarianos (Bell. Hisp. 20,1-3;21,3). En Vcubis parte de la legio Vernacula se pasa a César -en concreto, ocho centuriones acorazados "centuriones loricati» $(X X, 4)$, que se supone que se cambiaron de bando con sus soldados-.

$\mathrm{Cn}$. Pompeyo ordenó que incendiaran la ciudad puesto que sabía que la tenía perdida a manos de César (XXVII,4).

Hispalis: El Bell. Hisp. señala que dentro de la ciudad había un grupo muy numeroso de partidarios de Pompeyo ( $X X X V, 2$ ), y este tuvo su campamento próximo a la ciudad (XXVII, 3). Allí estaba un tal Filón, pompeyano, que tenía influencia en toda la Lusitania, lo cual se traduce en apoyo militar, lusitanos que van a luchar en Hispalis (XXXVI, 1).

A Hispalis se llevó la cabeza de Cn. Pompeyo (XXXIX, 3), muerto cuando escapaba de las tropas de César en el 45 a.C. (XXXVII-XXXIX), y César, después de la campaña convoca en la ciudad una asamblea: les reprocha la ausencia de apoyo a sus habitantes y a otras poblaciones (que le debían ya que él favoreció a la provincia), les condena por su ataque a magistrados romanos y a Casio, y también se muestra disconforme por el apoyo que concedieron a Cn. Pompeyo (XLII, 3-4).

Hemos observado en el Bell. Hisp. que los seguidores de Cn. Pompeyo aplican una táctica o estrategia bélica recurrente cada vez que, asediada una plaza suya por César, la consideran perdida: escapan dejando tras sí incendiada la ciudad o el campamento; ejemplos de esto los tenemos en el caso de Vcubi (XXVII, 4), Ategua (VII, 1), Castra Postumiana $(X, 2)$. Pero en el caso de Hispalis César tiene miedo de que los pompeyanos dañen la ciudad, y por ello permite a los lusitanos, que estaban dentro, que hagan una salida por la noche (XXXVI, 2). Creemos que este dato es un claro indicio de la importancia que la ciudad de Hispalis tenía en estos momentos para César.

25 Bell.Hisp. XIII, 4: “...postero die ad murum opus facere coeperunt et bene magna prioris muri parte deiecta..." (al día siguiente comenzaron obras de asedio junto al muro y gran parte del primer muro fue demolida). 
Hasta: Sabemos que obtuvo el estatuto de colonia, aunque la fecha de la deductio es dificil de precisar (hay diferentes teorias: antes, con César, o después), porque no aparece el nomen «lulia» en la titulación de la coIonia, pero hay autores que aún así defienden la existencia de este título para la colonia, guiándose por el ejemplo de Hispalis, que, siendo también lulia, en la obra de Plinio este título aparece omitido.

En el Bell. Hisp. se habla de que allí unos equites romani se pasaron a César (26, 1-2); luego se vuelve a hacer referencia a ella cuando se produce su rendición tras Munda $(36,4-5)$.

Urso: Llamada en el Bell. Hisp. Vrsao. Famosa por sus buenas murallas de defensa ("quod oppidum magno munitione continebatur», $\mathrm{XLI}, 3$ ). $\mathrm{Cn}$. Pompeyo enviaba cartas a los habitantes de Urso para mantenerlos fieles a su causa (XXVI, 3).

Se produjo su deductio tras Munda por obra de César, pasándose a titular Colonia Genetiva lulia Urbanorum Urso.

Carteia: Pompeyo tiene que abandonarla por disensiones internas entre sus habitantes (en principio era filopompeyana): había dos bandos en la ciudad, uno favorable a Pompeyo y otro a César (XXXVII, 1), pero se terminó decantando por este ; sus habitantes se apoderan de $\mathrm{Cn}$. Pompeyo $(X X X V I, 1)$ que pretendía escapar por su puerto, ya que la ciudad era una importante base naval, un praesidium nauale (XXXII, 6) en el que estaban disponibles veinte naves (XXXVII, 2).

Gades: Base de la flota al mando de Didio (XXXVII, 2), quien se encargó de perseguir a Pompeyo que tomó las veinte naves de Carteia para escapar.

Castra Postumiana: Alli fue levantado un fortín por César para proteger su campamento de Ategua ; se encontraba a unos 4.000 pasos de este (VIII, 6). El topónimo se debe al procónsul de la Hispania Ulterior del 180179 a.C., C. Postumio Albino. En el Bell.Hisp. se dice que era: "excellens natura» (destacado en altura por su naturaleza).

Hay autores ${ }^{26}$ que señalan que el factor fundamental de romanización es la política llevada a cabo por César en Hispania mediante la creación de colonias y municipios.

Blázquez señala que en el sur de la Citerior César creó cuatro colonias durante su etapa de dictador (lulia Romula Hispalis, Hasta Regia, Colonia

26 Blazquez Martinez, J.M.: «Estado de la romanización de Hispania bajo César y Augusto", Emerita 30 (1962). Gonzalez Roman, G., Marín Diaz, Mª, A.: Op.Cit. pág. 26. 
Genetiva lulia Urbanorum, y Claritas lulia), y que concedió el estatuto de municipio romano a Gades.

Haciendo un análisis del Bellum Hispaniense González Román llegó a la conclusión de la existencia de ciudadanos romanos en la península. Según este autor, un número considerable llegaría a la península como parte del acompañamiento de César, pero también, naturalmente, ya existía población romana asentada en la península ${ }^{27}$.

En este sentido también Roldán Hervás ${ }^{28}$ señala una la existencia de una importante colonización de carácter agrario en la península realizada durante el período republicano anterior a la guerra civil, lo cual se explicaría tanto por la existencia de una crisis agraria en la península itálica como por la necesidad de tener población de capacidad militar en la península para controlar a celtíberos y lusitanos, con lo cual se cederían lotes de tierra en Hispania a los veteranos licenciados del ejército romano que hubiese combatido en la península.

Entre las muchas ciudades hispanas afectadas por esta colonización debemos destacar las de Ilerda y Munda, cuyas fundaciones agrícolas tuvieron lugar en la primera mitad del siglo I a.C. ${ }^{29}$.

La zona de acción en el Bellum Hispaniense se concentra, como ya hemos mencionado, en el sur de la península, en lo que posteriormente será el núcleo de la provincia Baetica. Por ello y debido a esta concentración de la actividad militar, aumente el número de ciudades hispanas implicadas en el conflicto que unos años antes tras la batalla de llerda como nos relata la obra de César, tal vez debido a que en este primer encuentro de los dos ejércitos en tierras hispanas tiene mayor importancia la actividad en el norte puesto que era allí donde estaban centradas las tropas del enemigo pompeyano. En la obra de César, el viaje hacia el sur por tierras hispanas se debe más a razones políticas que a militares, es decir, que en el sur no había un ejército pompeyano al que atacar, pero sí había ciudades importantes, como Corduba a las que debía ir para afirmar su autoridad y poner la provincia bajo sus órdenes.

En cambio, en los enfrentamientos que relata el Bellum Hispaniense, el sur peninsular, y más concretamente la zona central de la posterior provincia Bética, tiene un marcado carácter militar debido a la insurrección

27 Gonzalez Roman, G.: Op.Cit, págs. 26 ss.

28 Roldán Hervás, J.M.: Ejército y sociedad en la España romana, Universidad de Granada, 1989, pág. 73.

29 Roldán Hervás, J.M.: Op. Cit., pág. 74. 
de ciudades hispanas contra la mala gestión de Casio Longino, alentadas por los seguidores de los hijos de Pompeyo, que llegan a la península para sacar provecho de ese foco inicial de descontento.

Las ciudades importantes de esta zona sur de la provincia Citerior ya visitadas militarmente en la campaña del 49-47 a.C. como Corduba, Hispalis, y Gades, vuelven a ser de vital importancia, en cuanto a su control, en la segunda fase de la guerra, contra los hijos de Pompeyo, debido a que su control es necesario para alcanzar la victoria (con estas ciudades a favor, el ejército consigue avituallamiento (existencia de comercio en Hispalis y Gades), tiene facilidad de comunicación con Roma, controla las principales vías de comunicación, y tiene en su poder los puntos políticoadministrativos de la región - Corduba-).

Pero también aparecen en los años 46-45 a.C. ciudades entremezcladas en el conflicto que no se habían mencionado en el primer relato cesariano, como Vrso, Vlia, Vcubis, Hasta, Ategua,... que entran en conflicto por primera vez de parte de uno u otro bando. Este tipo de alianzas o apoyos hacia una $u$ otra facción se explican en buena medida por el interés de «estar con» el bando vencedor para evitar represalias (saqueo de la ciudad, imposición de tributos abusivos por parte de Roma, negación de su autoridad interna, etc.). Esto es lo que sucedería en la mayoría de los casos. También el factor del clientelismo político llevado a cabo por los protagonistas en los años anteriores al conflicto e incluso durante la guerra movería a este juego de alianzas a ciudades como Vlia, defensora de los intereses de César desde un primer momento, Ategua, fuertemente pompeyana, o Gades, que se movió en ambos bandos dependiendo de las influencias político-militares a las que se vió sometida.

Es más discutida la posibilidad de adhesión a un determinado bando por «ideales políticos», cuestión que estaría directamente determinada por la existencia de población romana dentro de propia ciudad.

En este período, las ciudades de cierta entidad política y económica dentro de la península, y que estaban más relacionadas con el mundo romano eran Tarraco en el norte peninsular, y Corduba y Gades en el sur.

A partir de esta circustancia, creemos que la conocida batalla que tuvo lugar en llerda y sus inmediaciones está directamente relacionada con la lucha por el control del puerto de Tarraco, puesto que teniendo este como base o como punto de apoyo es muy fácil la llegada de ayuda desde Italia (provisiones y tropas). Probablemente las actividades bélicas no se llevaron a las cercanías de Tarraco para no entorpecer la actividad del puerto romano. 
Tarraco fue transformada en colonia tras la victoria de César, pasando a llamarse Colonia lulia Vrbs Triumphalis Tarraco, haciendo referencia a la victoria de César (bien a la victoria de llerda o bien a la victoria total cesariana de Munda).

En Tarraco se ha encontrado una doble inscripción dedicada a Pompeyo por una de sus caras, mientras que por la otra quedó dedicada a un legado de César, P. Mucio Escévola ${ }^{30}$. La inscripción a Pompeyo se fecha en los años 77-72 a.C., momento en que Pompeyo es proconsul de la Hispania Citerior; la inscripción cesariana es posterior, fechada en torno al año 61, cuando César es designado propretor de la Ulterior.

Esta inscripción, por lo tanto, respondería a una política de captación de clientelas sucesiva en el tiempo: primero sería hecha por Pompeyo y años más tarde por César, provocando cada uno una adhesión a su persona aprovechando la estancia en tierras hispanas debido a su cargo.

La inscripción se ha querido ver como el reflejo de una especie de "toma de posiciones» en cuanto al establecimiento de alianzas con uno y otro personaje que estaría determinado por la inestabilidad política existente dentro de la propia ciudad en los años previos al estallido de la guerra civil, y que se decantaría en un momento por una fidelidad manifiesta hacia el vencedor del conflicto ${ }^{31}$. Esta interpretación, a nuestro juicio, llevaría a afirmar la consciencia de los habitantes de Tarraco de la situación política romana, intentando sacarle su beneficio a las circunstancias bélicas, cosa que nos parece bastante improbable. Más bien parece ser el fruto de diferentes "campañas de captación de clientes" hechas por los romanos, primero por Pompeyo y sus seguidores, y luego por César y los suyos, y debiendose a la presencia o influencia de ambos personajes en la ciudad de Tarraco.

En cuanto a la ciudad de Gades, posiblemente los romanos tenían muchos intereses en una ciudad quie ya llevaba tiempo dentro de la órbita romana, además de tener un alto grado de romanización. Según nos relata la obra de César, fue un punto de construcción naval pompeyano (diez naves de guerra construidas por orden de Varrón).

Ya en el primer año de la guerra en Hispania, César le concede a la ciudad el estatuto de municipium ciuium romanorum, dándole la ciudadanía romana a sus habitantes (año 49 a.C.) ${ }^{32}$. César entró por primera vez

\footnotetext{
ALFOLDY, G.: Die Römischen Inschriften von Tarraco, berlin, 1975, n.․ 1,2.

Prieto, A.: “Tarraco», Dialogui di Archaeologia, 1992, pág. 86 ss.

Bell.Civ. XVIII, 1.
} 
en contacto con la ciudad en el año 68 a.C. cuando viajó a la península en calidad de cuestor del propretor Cayo Antistio Veto, y siempre pareció concederle un trato favorable, sobre todo desde su amistad con Balbo.

Hispalis fue en su primer momento una ciudad anticesariana, como también lo fueron Vcubi, Vrso, y Hasta. César las promovió a la categoría de colonias ${ }^{33}$.

Pero bajo esta aparentemente positiva promoción del estatus ciudadano hay un hacho fundamental y lógico: la promoción del estatus no era para los nativos que le opusieron resistencia, sino para los soldados veteranos del ejército de César asentados en esas ciudades tras su licenciamiento: César les concede tierras como merecido premio por su labor en los años en el ejército en territorios hostiles a su autoridad, porque, a la vez que «paga» a sus soldados, se asegura el control y sometimiento de unas tierras que apoyaron al enemigo.

Además de este carácter estratégico-militar, en el caso de Hispalis actúa otro factor de naturaleza económica, puesto que la plaza de Hispalis supone el control comercial del tráfico por el río Guadalquivir.

El resto de las ciudades que se vieron afectadas por el conflicto, de menor entidad que las anteriormente comentadas, estuvieron influenciadas fundamentalmente por el hecho de que su situación geográfica era muy cercana a los diferentes escenarios de los enfrentamientos, y por lo tanto se vieron afectadas sobre todo en lo concerniente al abastecimiento de viveres y forraje para los romanos, y, dependiendo de los casos, también en la aportación de hombres, siempre en virtud del vínculo de clientela que se hubiera establecido con los romanos.

También influye en buena medida la presencia de colonos romanos en zonas próximas o anexas a estas comunidades para mantenerlas bajo control romano - como ya señalamos la presencia de estos colonos en diferentes puntos de la península se debe a una colonización de base agrario-militar llevada a cabo durante el siglo I a.C. hasta la guerra civil-, y que por lo tanto, están influyendo en el apoyo de estas poblaciones a uno u otro bando, en virtud de los intereses políticos de estos colonos. En este contexto podría explicarse la intervención de Italica a favor de César en la guerra contra los legados de Pompeyo en torno al año 49 a.C. y su ausencia en los años 46-45 a.C. En Italica habían sido asentados soldados romanos e itálicos por Escipión en el año 206 a.C. tras la batalla de llipa.

\footnotetext{
Knapp, R.: Roman Cordoba, Classical Studies, Vol. 30, California, 1983, pág. 28.
} 
Lo mismo sucederia con el caso de Carteia, mencionada únicamente en el Bellum Hispaniense, y que estaba directamente ligada al mundo romano puesto que desde el año 171 ostentaba el título de "colonia latina", siendo la primera ciudad de provincias a la que se le concedió la categoría de colonia. Corduba también tenía un componente romano en su población y era colonia latina.

Una cuestión que nos ha llamado especialmente la atención es el posible interés económico de César en las zonas en las que centra su actividad, primero militar y luego organizadora del territorio o administrativa, puesto que las zonas por las que se centra su actividad suelen tener una importante característica en común: la proximidad a los yacimientos minerales, cuestión señalada por Roldán Hervás quien ya apuntó que la actividad de César era de carácter socio-económico y político ${ }^{34}$.

Para valorar este aspecto económico de la actividad cesariana es interesante atender a los estudios existentes sobre la zona minera de Cástulo -en Sierra Morena- donde los romanos obtenían hierro ${ }^{35}$ y plata ${ }^{36}$. A. González ${ }^{37}$ ha apuntado que el cese que se registra en esta explotación minera desde mediados del siglo । a.C. está directamente relacionado con el desarrollo que la guerra civil entre César y Pompeyo tiene en sus cercanías ${ }^{38}$.

En este sentidc Blázquez ${ }^{39}$ afirma (basándose en un análisis de las monedas) que las minas de Cástulo estuvieron en explotación desde el siglo I a.C. al II-III d.C., siendo interrumpidos los trabajos por causa de la guerra civil hasta la primera mitad del siglo I. Sin embargo, aunque las minas continúan en explotación hasta el siglo III, hay que señalar que su producción entra en un claro declive desde el período de guerra, e incluso después de terminado el enfrentamiento en Hispania entre César y Pom-

34 Roldán Hervás, J.M.: Op. Cit., pág. 75

35 En el análisis de minerales realizado en el poblado de La Muela -Cástulo - las cantidades más elevadas correspondian al hierro. Cf. estudio realizado por M. Lamela en: BLÁZQUEZ MARTINEZ, J.M.: Gastulo V, Madrid, 1985.

${ }_{36}$ Estrabón refiere la existencia de pequeñas cantidades de plata que aparecen mezcladas con un «plomo fósil» lo que hace improductiva su explotación (Str. III, 2, 11). Sin embargo, en otros pasajes cita a Cástulo como «Mons Argentariu» (Str. III, 2, 11).

Blázquez nos habla de la importancia argentífera de las minas de Cástulo. BцÁzQUEZ MARTínEZ, J.M.: Historia económica de la Hispania romana, Madrid, 1978, pág. 40.

37 Arévalo González, A.: «Sobre la circulación monéraria de la ciudad de Sísapo (Almodóvar del Campo, Ciudad Real)", Anejos de AEArq : La ciudad hispánica, ciudad y territorio CSIC, Madrid, 1995, pág. 132.

38 García-BELLIDO, Ma.P.: Las monedas de Cástulo en escritura indigena. Historia numismática de una ciudad minera, Barcelona, 1982, pág. 110-115

39 Blázouez Martinez, J.M.: Castulo V, Madrid, 1985, pág. 39 
peyo, se tardan bastantes años en activar de nuevo la producción de la mina.

Este mismo cese en la explotación de minerales se registra también en otras minas de Sierra Morena ${ }^{40}$.

Según estos datos, las causas del declive de Cástulo sólo estarían en el abandono de los establecimientos ante la inestabilidad y la amenaza militar. Sin embargo, es curioso ese hecho ya comentado de que se hubiese tardado tanto tiempo en volver a ponerlas en explotación después del cese de las hostilidades.

Este elemento, puesto en relación con el hecho de un nuevo inicio de explotación minera en la zona conocida como la Beturia, nos lleva a pensar en la posibilidad de este nuevo núcleo minero de la Beturia, viniese a tomar el relevo a Cástulo de la producción del sur peninsular, para lo cual argumentamos una serie de factores que favorecen a esta región frente a las ya tradicionales: La Beturia está situada en una zona que prácticamente no se vió afectada por la guerra civil, y que además, al no ser explotada con anterioridad de manera más o menos intensiva, ofrecería a los romanos unos minerales más abundantes y de más fácil explotación.

El esquema explicativo que nosotros proponemos es el siguiente: la decadencia minera de la región de Cástulo impulsó el desarrollo de una región altenativa, la Beturia, explicación que estaría sustentada por una política colonizadora de época cesariana muy próxima a las minas de esta región ${ }^{41}$, que respondería a la necesidad de tener un lugar de viviendasdormitorio para la población que trabajaba en las minas, y el consecuente control romano tanto de las minas como de esta población.

Aún así, como ya señalamos más arriba, Cástulo continúa en actividad al menos siglo y medio después de este intervalo inactivo y posiblemente los romanos combinasen la explotación de ambas regiones mineras.

Por otra parte, hay que señalar la importancia que, presumiblemente, Cástulo tuvo para César, puesto que la existencia del título de "Castulonenses Caesarii luvenales» es recogido por Plinio en su obra casi un siglo después (NH, III, 25); probablemente este fue concedido por César en la conocida asamblea celebrada en Corduba tras la victoria de $/ l e r d a{ }^{42}$ del año 49 a.C.

40 Blázquez Martínez, J.M. : Op. Cit. pág. 40.

41 Canto, A.M ${ }^{2}$.: «La Beturia Céltica. Introducción a su epigrafía», Cuadernos Emeritenses 9 , Mérida 1995, pág. 311-315.

42 BlázQuez Martínez, J.M.: Castulo /, Madrid, 1975, pág. 30. 
Hispania era para Roma una fuente importante de abastecimiento de minerales, al menos para el período de tiempo del siglo । a.C. al । d.C. como ha señalado $A$. Curchin ${ }^{43}$, aunque también señala que las minas alcanzaron su mayor producción en el siglo " ${ }^{44}$ y que en estos siglos el objetivo de los romanos era la minería de la plata y no la del cobre.

Durante la estancia de César en Hispania no se habilitaron las medidas necesarias para una explotación más o menos sistemática orientada hacia estos intereses generales de los que habla Curchin, aunque sí podemos intuir una especial atención dedicada a los distritos o zonas que contaban con este tipo de recursos. Ya hemos mencionado el evidente interés minero sobre la región de la Beturia (rica en hierro y plomo, también algo de plata), pero creemos que este es un factor que podemos encontrar en otros casos analizables, como por ejemplo Carthago Nova, que poseía unas minas puestas en explotación descie el II a.C., y que fue también objeto de una actuación no de César directamente pero sí cesariana en cuanto que fue llevada a cabo por sus partidarios, en este caso por su lugarteniente Lépido, como se deduce de los datos numismáticos registrados en la propia ciudad ${ }^{45}$.

La actividad de César sobre suelo hispano después de finalizada la guerra civil (que también tuvo lugar durante el transcurso del propio conflicto) se ve condicionada por una serie de factores que ya vienen determinados por el propio contexto, en otras palabras, su actividad se va a regir por los mismos patrones que ya influyeron en anteriores políticas de ocupación romana de la península, es decir, que se va a circunscribir a las zonas más romanizadas, que, por lo tanto, tuvieron mayor contacto con Roma desde fechas anteriores. Hacia ellas se va a centrar la política desarrollada por César, cosa lógica teniendo en cuenta la presencia en esas ciudades de población romana o itálica. Además es notable que también despiertan el interés de los romanos las ciudades que tienen algún tipo de interés económico, como puede ser la existencia de centros o puntos de comercio orientado hacia Italia (como Tarraco, Hispalis, o Gades), o la existencia de una zona rica en minerales en sus proximidades (región de la Beturia, Carthago Noua).

43 A.CuRchin, L.: Op.Cit. pág. 179. Apunta este autor que después del siglo id.C. otras zonas toman el relevo a Hispania en el abastecimiento-comercio de minerales, como Britania o la Dacia.

44 A. CuRCHIN, L.: Op.Cit. pág. 181.

45 La numismática registrada en esta ciudad le atribuye la fundación a Lépido. Hay autores que señalan que el origen de la colonia se puede deber a César, siendo Lépido el que la lleva a cabo, debido a la prematura muerte de aquel, basándose para esto en la aparición del apelativo lulia. Nosotros pensamos que la aparición del apelativo no tiene porqué estar indicando una actuación directa de César, y la concesión de este al municipio, pudo ser dada por Lépido con la intención de hacerle el honor debido a César, que acababa de morir asesinado. 
Las ciudades por las que van teniendo lugar las diferentes batallas entre ambos bandos son escogidas en virtud del movimiento de las tropas de los ejércitos, que, a su vez, se mueven en función de los pactos de alianza y relaciones de clientelaje establecidos con la población. Este quizás es el condicionante más importante debido a que los diferentes ejércitos intentan en todo momento llevar la guerra hacia escenarios que les son respectivamente favorables en los que pueden contar con la ayuda militar de las poblaciones con las que anteriormente han establecido estos pactos. A este respecto volvemos a señalar la crucial importancia de este hecho puesto que el juego de alianzas es el que determina la victoria de uno u otro bando. Asimismo es importante la existencia de abastecimiento susceptible de ser utilizado por los romanos, para los soldados y para las caballerizas.

\section{BIBLIOGRAFÍA}

César, J.C.: De Bello Ciuile. I-III Libri. Traducción de J. Calonge Ruíz, Ed. Gredos, 2ª Ed., Madrid, 1983.

Bellum Hispaniense. Traducción de José Castro Sánchez, Madrid, Ed. Clásicas, 1992. Comentarios a la guerra civil. Traducción de José Enríquez González. Ed. Alianza, Madrid, 1985.

Memorias de la guerra civil. Traducción de Sebastián Mariner Bigorra, Barcelona, 1958. La Guerre Civile 1-II, edición de P. Fabre, Budé 1936.

Ciceron, M. T.: Cartas a Ático. Traducción de Miguel Rodriguez-Pantoja Márquez. Ed. Gredos, Madrid, 1996.

Letters to Atticus. Traducción inglesa de Winstedt, M.A., Harvard University Press, 1946.

Blazquez Martínez, J.M.: Castulo I, Madrid, 1975.

Castulo V, Madrid, 1985.

"Cástulo en las fuentes histórico-literarias". Oretania 21 (1965).

BRuNT, P.A.: Italian Manpower 225 BC-14 AD, Oxford, 1971.

CANTO, A.M,": "La Beturia Céltica. Introducción a su epigrafía», Cuadernos Emeritenses, Mérida, 1995, págs. 293-327.

Curchin, L.: España romana, Madrid, 1996 (ed. London \& New York, 1991).

Dialogi di Archaeología, Congreso histórico-arqueológico hispano-italo, 1989. Ed. Roma,1992, $n^{\circ} 1-2$.

Dopico Caínzos, $M^{z}$ D.: "Los conuentus iuridici. Origen, cronología y naturaleza histórica", Gerión 4, Madrid, 1986.

La Tabula Lougeiorum. Estudios sobre la implantación romana en Hispania, Vitoria-Gasteiz, 1988.

Ferreiro López, M.: César en Hispania (tesis en microfichas), Madrid, 1981. "La campaña militar de César del año 61 ". Actas del I Congreso de Historia Antigua, 1988.

García y Bellido, A.: "Las colonias romanas de Hispania», AHDE, XXIX (1959), págs. 447 513.

GonzÁlez Román, G.: “El Bellum Hispaniense y la romanización del sur de la península". Hispania Antiqua, 11-12 (1981-85).

González Román, G., Marin Diaz, MA.: "César contra Pompeyo. La guerra civil en Hispania (49-45 a.C.), Historia 16, 1984, pág. 62 ss.

Grant, M.: From Imperium to Auctoritas, Cambridge (1946) 1969.

HARMAND, J.: “Caesar et l'Espagne durant le second bellum ciuile". Legio VII, 1970, págs. 181206. 
RambaUd: «Le camp de Fabius près d'llerda. Un probleme césarien (Bell.Civ.1, 40)». LEC, 44, 1976.

L'Art de la déformation historique chez César, Paris, 1966.

ROLDÁN HERVÁs, J.M.: Ejército y sociedad en la Hispania romana, Granada, 1989.

Hispania y el ejército romano: contribución social de la España antigua, Salamanca, 1974. "El elemento indígena en las guerras civiles en Hispania. Aspectos sociales", Hispania Antiqua II, 1972, pág. 77-123. 